\title{
Numerical Design and Experimental Validation of a Plastic 3D-Printed Waveguide Antenna for Shallow Object Microwave Imaging
}

\author{
Luca Bossi $^{1}$ D Pierluigi Falorni ${ }^{1}$ - Saverio Priori ${ }^{2} \cdot$ Roberto Olmi $^{2}$. \\ Lorenzo Capineri ${ }^{1}$
}

Received: 3 February 2021 / Revised: 3 February 2021 / Accepted: 26 April 2021 /

Published online: 9 May 2021

(C) The Author(s) 2021

\begin{abstract}
Microwave imaging of shallow buried objects has been demonstrated with holographic radar for landmine detection, civil engineering and cultural heritage. A key component of this system is the antenna based on a truncated cylindrical waveguide with two feeds. This paper investigates for the first time a manufacturing technology based on the 3D printing of a volumetric cylindrical plastic antenna. The investigation of this manufacturing technology was motivated by the reduction in the antenna size and customization of the electromagnetic characteristics to the radio frequency electronics mounted on the robotic scanning system. The antenna that was designed using a simulator and filled with polylactic acid plastic material (relative dielectric permittivity $\varepsilon r=2.5$ ) is compared to the metal antenna, both operating at around $2 \mathrm{GHz}$. The goal was to replicate the characteristics of the void core antenna to be able to provide the same quality/information of the microwave images of shallow buried objects. Finally, we compared the scan results of dielectric and metal targets both in the air and in natural soil. From the observation of some of the characteristics of the images, such as dynamics, morphology of the target, signal-to-noise ratio, and operating distance, we demonstrate that 3D printing for volumetric cylindrical waveguide antenna could be used to obtain compact and easily adaptable antennas for different applications in remote sensing.
\end{abstract}

Keywords Holography $\cdot$ Microwave antennas · Microwave imaging $\cdot$ Millimeter wave radar $\cdot$ Plastic core antenna $\cdot$ Cylindrical waveguide $\cdot$ Radar imaging $\cdot$ Threedimensional printing

Luca Bossi

1.bossi@unifi.it

Extended author information available on the last page of the article 


\section{Introduction}

Microwave holographic radar imaging has been explored in the last decade for finding successful applications in remote sensing of shallow buried objects and a review of the most promising applications with portable instruments can be found in [1-3]. During this period several research developments have been reported regarding the microwave imaging algorithms, scanning methods and portable electronics that facilitate the use of this method in real-life applications. From the point of view of technological development in the microwave fields the $3 \mathrm{D}$ printing of plastic components has surged due to low-cost instruments and plastic filaments becoming common. The 3D printing technology offers multiple features that lend itself to the realization of antennas or parts of them in the microwave field [4]. In the conventional manufacturing of microwave devices, increased complexity and/or customization leads to increased costs. Furthermore, when production is limited to a few prototype units, production costs are high. Three dimensional printing technology can be a valid solution for prototyping, because the cost for piece is independent from the number of piece built.

In modern communication systems (e.g., 5G technology), the used frequencies fall in the millimeter wave range. That has a limited range due to the propagation losses. For this reason, efficient and high gain antennas are needed. One method to improve the gain is to apply dielectric lenses over the source antennas, which can be integrated (Integrated Lens Antennas, ILA) [5-7]. The dielectric lens increases the directivity of the source antenna by transforming the spherical wave front of the radiated wave into a planar one. Three-dimensional printing allows great versatility in the choice of dielectric lens profiles, and plastic materials allow one to limit the weight and costs $[8,9]$.

Examples of high-gain passive antenna arrays have been produced, including the Ku-band folded Reflect array and Radial Line Slot Array (RLSA) with lowcost materials and printers [10].

In the literature there are examples of prototyping horn antennas and directional couplers using 3D printing [11-14], fractal bow-tie antennas (FBTA), spiral antennas, and Yagi-Uda antennas operating with a target resonant frequency of $2.45 \mathrm{GHz}$ [15]. With the further development of printhead materials and technologies, new structures with intertwined metallic and dielectric regions (e.g., dielectric charged antennas) can be produced using 3D printing. In addition, cavities can be formed to incorporate integrated radio frequency electronic devices within the antenna structure to achieve compact and improved-performance RF front ends.

The plastic materials used for additive $3 \mathrm{D}$ printing are polymers, with low toxicity, with melting temperatures typically between 180 and $240{ }^{\circ} \mathrm{C}$. The possibility of making filaments of composite materials, in which other materials are mixed with the plastic polymer, allows the creation of innovative filaments with interesting properties. For example, in the field of the microwave applications, mixtures of ceramic material can obtain higher and certified dielectric permittivity than is obtainable with only plastic polymers [16]. 
In the process of making a 3D printed antenna an important part is played by metallization. This can be achieved with the application of conductive paint, with metal adhesive sheets, but it can go as far as metal sputtering. The technique used affects the mechanical strength of the layer and the attenuation. The conductive paint offers a fairly easy application even on complex surfaces and forms a layer that has a typical thickness of $50 \mu \mathrm{m}$ for each coat. There are nickel-based conductive paints, such as the one used in this work, copper and silver-based paints, and silver-only paints. Each offers different attenuation characteristics ranging from around $60 \mathrm{~dB}$ for $100 \mu \mathrm{m}$ of nickel-based paint, up to $80 \mathrm{~dB}$ for silver-based paint at $2 \mathrm{GHz}$.

To our knowledge, the application of $3 \mathrm{D}$ printing to design a $2 \mathrm{GHz}$ truncated cylindrical waveguide antenna for a microwave imaging with portable instruments is presented for the first time in this power.

Our design started from scanning system specifications and then the simulator analysis of the electromagnetic field propagation in a 3D-printed volume. We evaluated the effects of surface roughness, execution times and geometrical deformations introduced by the non-ideality of the printer head positioning which are peculiar aspects of this choice to operate on the volume that must be studied.

The simulation made it possible to evaluate the behavior of the plastic materials and conductive paints, the dimensions and weight of the prototype, allowing us to make the choices in consideration of the cost-performance ratio of the raw materials [17].

The characterization of the built antenna allowed us to verify the differences with the simulated model and then proceed with the installation on a robotic scanning system and compare the performance with an equivalent cylindrical metal void core waveguide antenna.

We decided to use PLA because it is low cost, has relatively high dielectric permittivity $(\varepsilon r=2.5 @ 2 \mathrm{GHz})$ compared to air, and it is easily available on the market. The choice of a common plastic material implies the need to consider the variability in its physical characteristics, such as the dielectric permittivity and the tolerance of dimensions. Therefore, we considered this aspect during the production.

The antennas were compared in the laboratory to characterize their electromagnetic behavior. Subsequently they were installed on board the mechanical scanning hardware, connected to the microwave RADAR system, and used to acquire images of some objects that we took as reference: first, in the laboratory, a $10 \mathrm{~cm}$ square metal reflector with some through holes of different sizes and an empty plastic box of $7.5 \mathrm{~cm}$ in diameter, then, in the outdoor field test, a previously buried anti-personnel mine simulant, in order to simulate the conditions of a real minefield. The process used for designing, simulating and building the plastic core prototype is described. Then, we outline the experiments in the laboratory and on a landmine simulant buried in outdoor soil. Following this is the discussion about the manufacturing process and the experiments results, showing how 3D printing technology represents a promising design process. 


\section{Materials and Methods}

On the basis of the criteria defined in the literature [2], two new antennas were designed and then modelled and simulated with CST Microwave Studio ${ }^{\circledR}$ software [18]. One is made of metal with void core and one with core in PLA plastic material. We chose this material because we aimed to construct a 3D-printable antenna and PLA is a common material, low cost, and has a typical dielectric constant value around 2.5 in the frequency range of interest (around $2 \mathrm{GHz}$ ), which is quite high amongst those in the portfolio of filament printing plastics. The waveguide antenna has PLA inside that fills the entire volume (colorFabb ${ }^{\circledR}$ PLA/PHA, PLA with added polyhydroxyalkanoate; colorFabb B.V., Belfeld, The Netherlands) and, as an external conductor, metallization was applied by spraying conductive paint (Copper-Nickel 841AR Super Shield ${ }^{\mathrm{TM}}$ Nickel Conductive Paint, MG Chemicals Ltd, Burlington, ON, Canada) [19]. The void core antenna was constructed by cutting and drilling a steel pipe. The antenna reflector is aluminum, which was molded by milling and pressing it in. For both antennas, the feeds were constructed with a straight quarter wave conductor soldered to a Sub Miniature A Connector (SMA)/ coaxial cable connector by soldering the feed to the core end of the coaxial cable side (Fig. 1).

Once the dimensions of the two antennas were defined, the simulation software exported the drawing in a compatible CSD (Cocos Studio Interface File) file format. The 3D drawings were then acquired with Autodesk Fusion 360 software (Autodesk, Inc., San Rafael, CA, USA). For the void core antenna, the processing board for production in the mechanical workshop was made; for the antenna in plastic, the $3 \mathrm{D}$ model was used as the basis for the slicing procedure using the same software and the final file was exported in standard triangulation language (STL) format for printing. The prototype was physically printed with the Anet A8 3D printer [20], a cheap printer available as an assembly kit and can be easily assembled anywhere, even in areas with limited financial resources.

Fig. 1 Mounted feeds. The

SMA/coaxial cable panel connector and the quarter wavelength soldered brass wire are visible

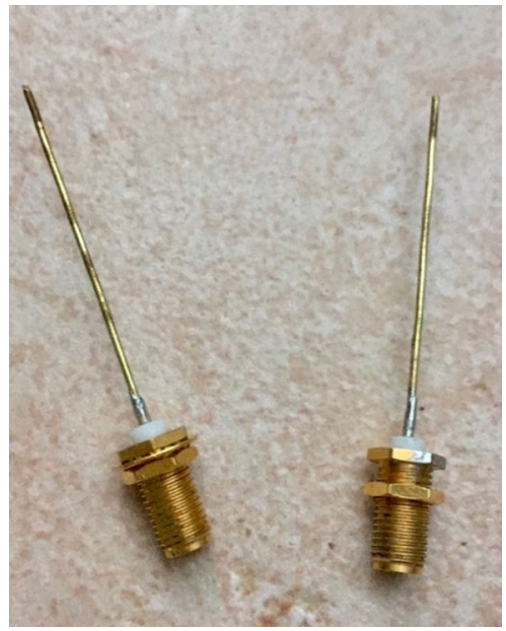


Once the feeds were assembled, the two antennas were characterized: the S (Scattering) parameters were measured using the radiation pattern in the anechoic chamber [21]. The two prototypes, connected to the same driving and control electronics, were mounted on the scanning device and the images obtained of some reference targets were compared. We compared the images by comparing the dynamics and standard deviation of each, as reported in Sect. 3.

\subsection{Design of Antennas}

Narrow band microwave radar antenna technology involves radiating a wave generated by a continuous single frequency signal over time [22-24]. The guide is excited by a linear quarter-wave feed positioned at a quarter of the wavelength in the guide from the rear reflector to obtain a phase overlap of the wave reflected inside the guide. The second feed, positioned on the same axis, diametrically opposite the first, receives the wave reflected from the outside by the possible target and, at the same time, receives the transmitted signal through direct coupling. In this way, interference between these two signals is generated on the receiving feed, which constitutes the hologram. For each point of the grid defined on the scanning plane, the value of the interference field is acquired, thus forming the holographic image. The image thus obtained can be used directly or further processed with inversion techniques typical of digital holography to reconstruct the electric field reflected in planes parallel to the scanning plane which can be chosen by defining the desired antenna plane distance.

Without loss of generality of the application of 3D printing technology, the two antennas were designed to be compatible with the radiofrequency electronics mounted on the robotic system [25] with operating frequency range of $(1.6,2.1)$ $\mathrm{GHz}$. As such, we designed the feeds impedances to match with output impedance of driving and receiving electronics.

Starting from the theory of truncated circular waveguide antennas [26], we obtained $2 \mathrm{GHz}$ antennas, as shown in Fig. 2, with their sizes reported in Table 1.

Then, the second feed was introduced (Fig. 3) and the geometry of the devices was modeled on a simulator to optimize the input and output impedance, bringing it closer to the nominal value of the connected electronic devices (the standard is $50 \Omega$

Fig. 2 Drawing of circular waveguide antenna

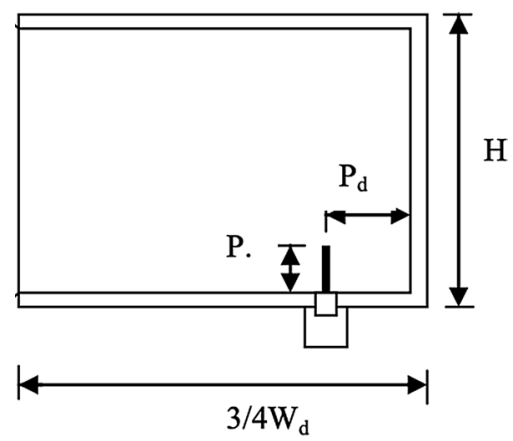


Table 1 Sizes of truncated circular waveguide antenna matched for $2 \mathrm{GHz}$

\begin{tabular}{lllll}
\hline Antenna & $\mathrm{Wd}[\mathrm{mm}]$ & $\mathrm{H}[\mathrm{mm}]$ & $\mathrm{P}_{\mathrm{d}}[\mathrm{mm}]$ & $\mathrm{P.}[\mathrm{mm}]$ \\
\hline Void core & 227.4 & 117 & 56.8 & 37.5 \\
3D-printed & 252.6 & 60 & 63.2 & 23.7 \\
\hline
\end{tabular}

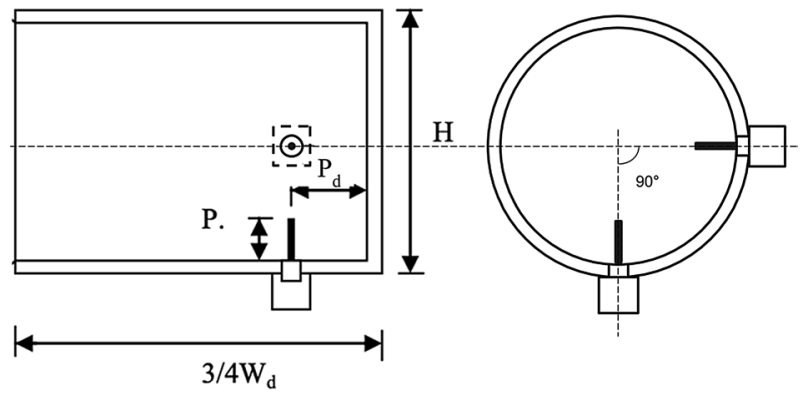

Fig. 3 Drawing of designed antennas

for the transmitter and $39.7 \Omega$ for the receiver (according with the datasheet of the device AD8302 input impedance @ $2 \mathrm{GHz}$ ) and maximizing sensitivity by trying to bring the value of the direct coupling signal closer to the level of the signal from the subsoil, which can, for example, be much lower than $100 \mathrm{~dB} \cdot \mathrm{m}^{-1}$ in loamy moist soil (Table 2).

After the antenna design and optimization in CST, we built and characterized the prototype and then we have taken the simulated model and we have modified it in order to make the simulated parameters coincide with the real ones.

\subsection{D Printing Process}

The major printing parameters are summarized in Table 3. The time required for the entire process was approximately $21 \mathrm{~h}$. Before proceeding with printing, a mechanical calibration process was followed to minimize the positioning errors of

Table 2 Sizes of designed antennas for operating frequency of $2 \mathrm{GHz}$

\begin{tabular}{lllll}
\hline Antenna & $\mathrm{W}_{\mathrm{d}}[\mathrm{mm}]$ & $\mathrm{H}[\mathrm{mm}]$ & $\mathrm{P}_{\mathrm{d}}[\mathrm{mm}]$ & $\mathrm{P} .[\mathrm{mm}]$ \\
\hline Void core & 166.7 & 117 & 41.3 & 34.2 \\
3D-printed & 170.8 & 62.2 & 56.3 & 21.5 \\
\hline
\end{tabular}

Table 3 Principal slicing settings

\begin{tabular}{lllll}
\hline Extruder size & Layer height & Infill $\%$ & Extrusion temperature & Extrusion speed \\
\hline $0.6 \mathrm{~mm}$ & $0.3 \mathrm{~mm}$ & 100 & $230{ }^{\circ} \mathrm{C}$ & $75 \mathrm{~mm} / \mathrm{s}$ \\
\hline
\end{tabular}


Table 4 PLA filament specifications provided by the producer

\begin{tabular}{llll}
\hline Filament diameter & Diameter tolerance & Density & Glass transition temperature \\
\hline $1.75 \mathrm{~mm}$ & $\pm 0.05 \mathrm{~mm}$ & $1.21-1.43 \mathrm{~g} \mathrm{~cm}^{-3}$ & $55^{\circ} \mathrm{C}$ \\
\hline
\end{tabular}

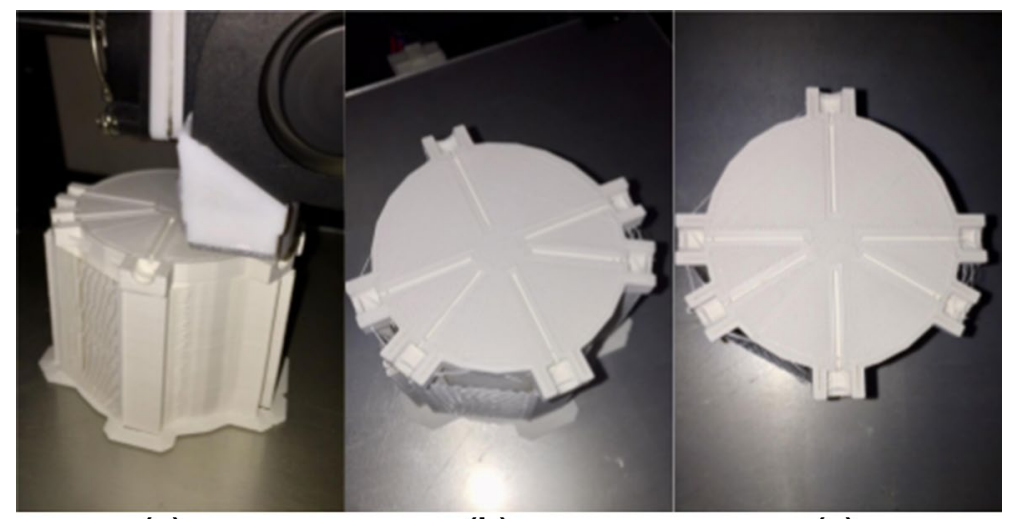

(a)

(b)

(c)

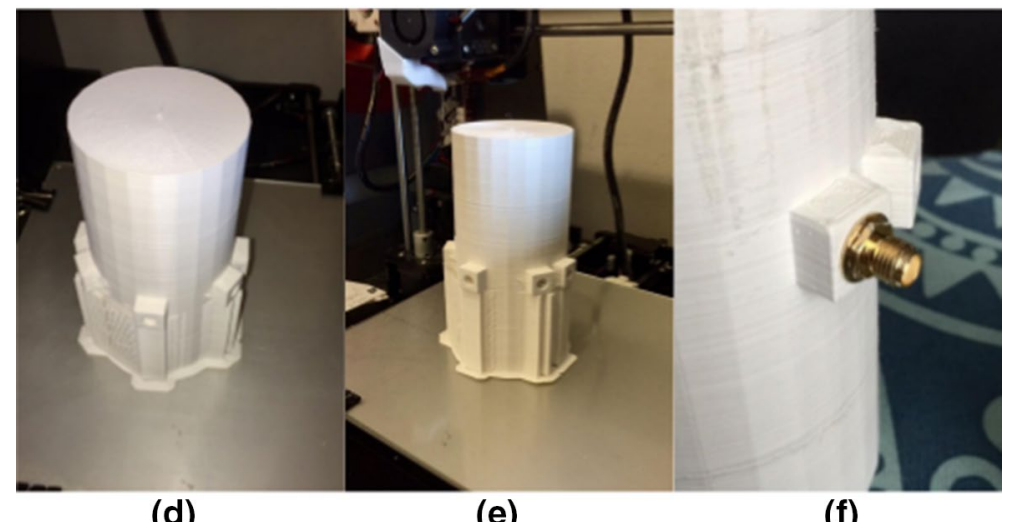

(d)

(e)

(f)

Fig. 4 Photographs from during the 3D printing process: $\mathbf{a}-\mathbf{c}$ before finishing the process, we can see the shape of the feed holes; $\mathbf{d}-\mathbf{f}$ at the end of the process, the external supports for the feed-mounting platform are shown

the extrusion nozzle. Borosilicate glass was applied to the printing plate and sprayed with hairspray to maximize the adhesion of the extruded material. During the printing process, the printer was kept in a controlled environment by isolating it with a cardboard box. Table 4 reports the main characteristics provided by the producer of the filament.

Figure 4 shows the images captured during the printing process.

The production process of the antenna terminates with painting. The first layer is a primer for plastic materials, the second includes three coats of nickel based 
conductive paint for a thickness of about $150 \mu \mathrm{m}$. According with manufacturer datasheet, in the range $1-10 \mathrm{GHz}$, the attenuation with two coats of paint is variable from -56 to $-74 \mathrm{~dB}$. Manufacturer also report that a layer of aluminum of equal thickness attenuates, at the same frequency about - $90 \mathrm{~dB}$. The reduced shielding has effects on the antenna gain. The research project considered also a low-cost production and the choice of this type of conductive paint was made on the basis of this parameter as well. There are conductive silver-based paints on the market with attenuation levels comparable to those of solid metal, but at a higher cost. However, our imaging application of the prototype is mainly in the near field and we notice that the reduced gain does not significantly deteriorate the images information content. The last layer is an acrylic paint for protects the substrate. The painting procedure steps are presented in the pictures in Fig. 5

\subsection{Matching Geometry of the Simulated Model to the Printed Plastic Prototype}

The printing of the plastic prototype, as expected, led to considerably different sizes and shapes compared to those of the model designed with the simulator (the error introduced initially by the printer is always in excess and is $2,27 \%$ for $\mathrm{W}_{\mathrm{d}}, 2,25 \%$ for $\mathrm{H}, 1,6 \%$ for $\mathrm{P}_{\mathrm{d}}$ ). Geometric defects occurred mainly due to the cheapness of the printer, which requires accurate calibration and does not guarantee the repeatability of long-term behavior. Moreover, there were also uncertainties due to the dielectric behavior of the material which, by choosing a common and non-certified filament, cannot be guaranteed. However, more expensive filaments with certified relative dielectric permittivity are available. The shape of the waveguide was slightly elliptical and the distance of the feeds from the reflector was reduced. For this reason, the model was adapted to the real dimensions and shapes and further modified, by acting on the length of the feeds, to bring the characteristics closer to those initially envisaged. The real sizes of the built plastic core antenna are shown in Table 5.

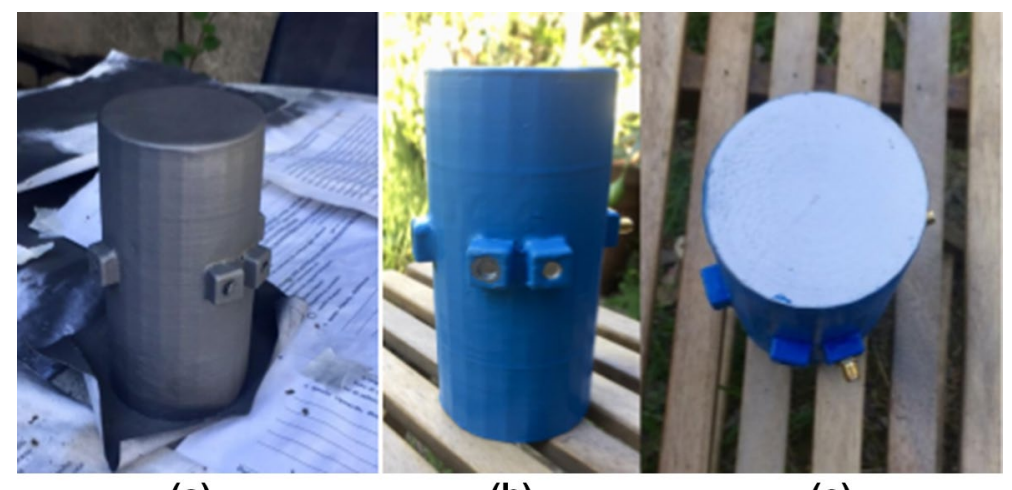

(a)

(b)

(c)

Fig. 5 Sequence of coating process: a after deposition of $150 \mu \mathrm{m}$ thickness (corresponding to three coats) of conductive paint (841-AR Nickel based paint); b, $\mathbf{c}$ after two coats of acrylic cyan paint 
Table 5 Sizes of 3D printed antenna after being built. D are the diameters of elliptic shape

\begin{tabular}{llll}
\hline $\mathrm{W}_{\mathrm{d}}[\mathrm{mm}]$ & $\mathrm{H}[\mathrm{mm}]$ & $\mathrm{P}_{\mathrm{d}}[\mathrm{mm}]$ & $\mathrm{P} .[\mathrm{mm}]$ \\
\hline 174.67 & $\begin{array}{l}62.4 \times 64.8 \\
\left(\text { elliptical } \mathrm{D}_{\min } \times \mathrm{D}_{\max }\right)\end{array}$ & 57.2 & 21.5 \\
& & & \\
\hline
\end{tabular}

\subsection{Measurements}

The built antennas (Fig. 6) were then characterized at the Nello Carrara Institute of Applied Physics (IFAC, Sesto Fiorentino-Florence, Italy).

For each prototype, the $\mathrm{S}$ parameters were measured using the Network Analyzer Keysight N9914A (Keysight Technologies, Santa Rosa, CA, USA). We proceeded by installing the antenna inside the anechoic chamber on a turntable using a low-reflectivity support. At a distance of $1 \mathrm{~m}$, a reference ridged-type antenna was placed at the same height from the ground as the antenna under investigation, with polarization first parallel, then orthogonal (Fig. 7).

The block diagram in Fig. 8 describes the interconnections between the devices.

The table was rotated in defined steps and the values of the $S$ parameters were acquired at each step. The same procedure was performed for each of the two feeds installed on the antenna. Referring to the gates indicated in Fig. 8, the radiation pattern is represented in terms of the $S_{21}$ parameter. Subsequently, since it is a RADAR antenna that measures an interference pattern, it is important to estimate the value of the direct coupling between the feeds, which constitutes the reference signal for the generation of the aforementioned interference pattern. The antenna, with the two feeds mounted (Fig. 9), was connected to the Network Analyzer (Model: Keysight N9914A).

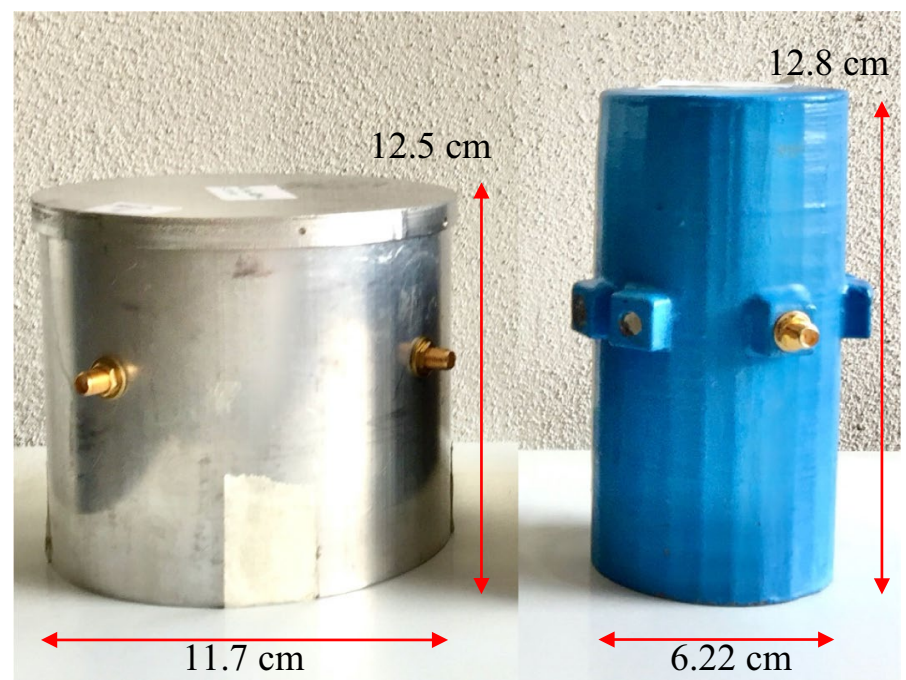

Fig. 6 Two built antennas. (left) The void core full metal antenna, (right) the plastic core antenna. With the antennas side by side, the differences in size are indicated on the image 


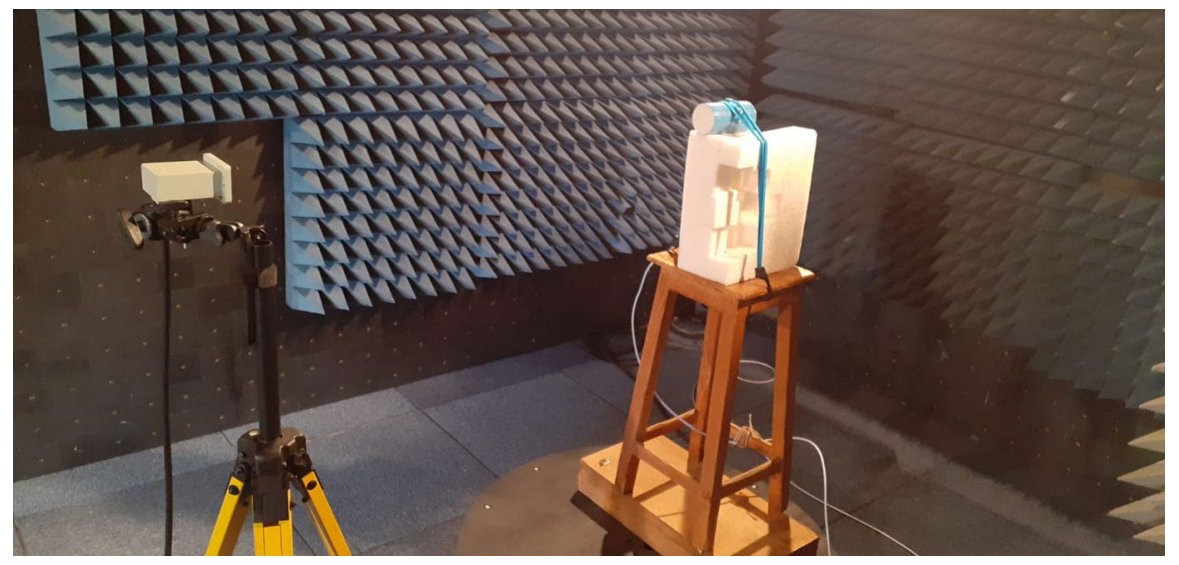

Fig. 7 Anechoic chamber setup for measuring the radiation pattern of the antennas. (left) The ridged antenna used as reference and (right) the plastic core antenna positioned on the rotating plate (on the floor)

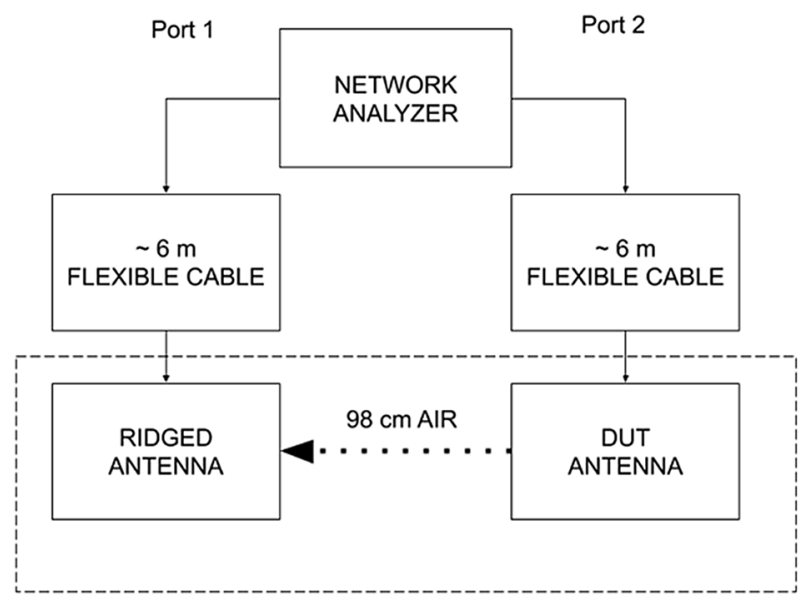

Fig. 8 Diagram of connections between the devices for measuring the radiation pattern of the antennas. The dashed rectangle represents the anechoic chamber. DUT is the Device Under Test

By orienting the RADAR antenna toward open space, the parameter $S_{21}$ was measured which in this case is representative of only the part of the transmitted signal that is coupled to the receiving feed, without adding the contribution of the received signal from an external reflection to the antenna (see Fig. 10). 


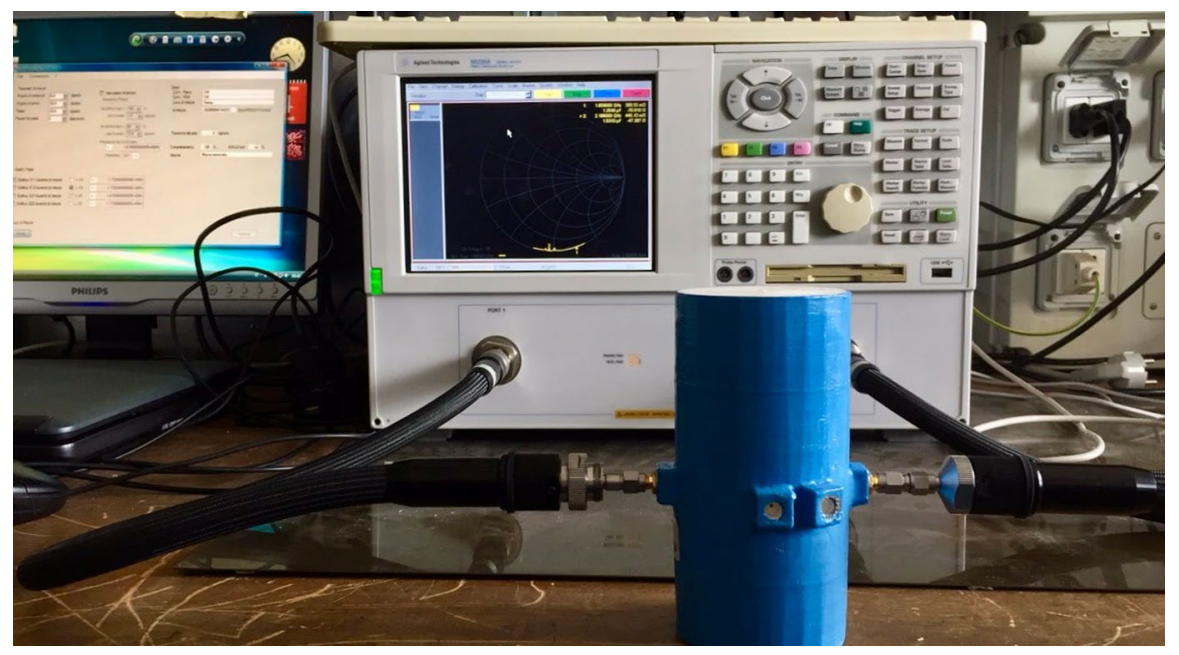

Fig. 9 Measurement setup for feeds direct coupling measurement

Fig. 10 Connections block diagram for measure of direct coupling between the antenna feeds. The dashed rectangle represents the anechoic chamber

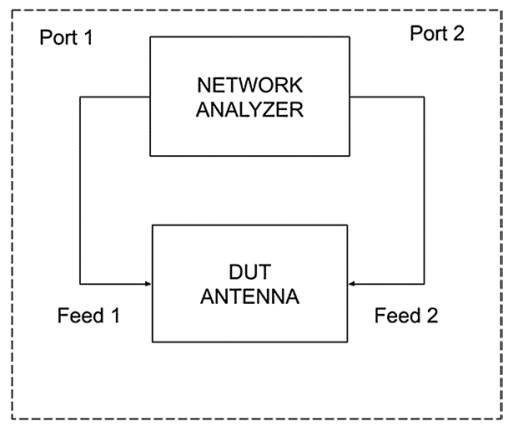

\section{Results}

\subsection{Simulation Results}

After optimization, the simulation results are shown in Fig. 11 for the $S_{11}$ and $S_{12}$ parameters and the radiation pattern for both antennas.

The diagrams show that the antennas matched for the $2 \mathrm{GHz}$ frequency and their levels of return loss were comparable $(-33.4 \mathrm{~dB}$ vs. $-36.5 \mathrm{~dB})$. The void core antenna shows a $-10 \mathrm{~dB}$ matching bandwidth, which is slightly higher than the plastic one.

Figure 12 shows the radiation patterns of the two antennas in the two polarizations. Table 6 reports the main parameters of the radiation. The radiation magnitude was about $3 \mathrm{~dB}$ lower in the case of the plastic core antenna. The aperture of the main lobe was higher in the plastic core antenna, which is better for holographic applications for acquisitions based on the synthetic aperture radar concept. The 

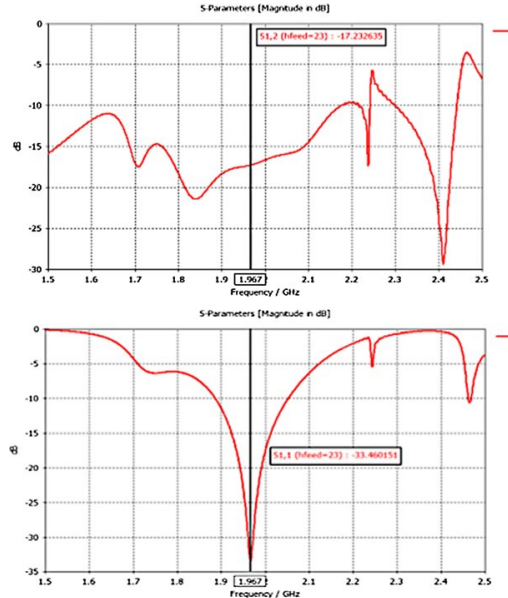

(a)
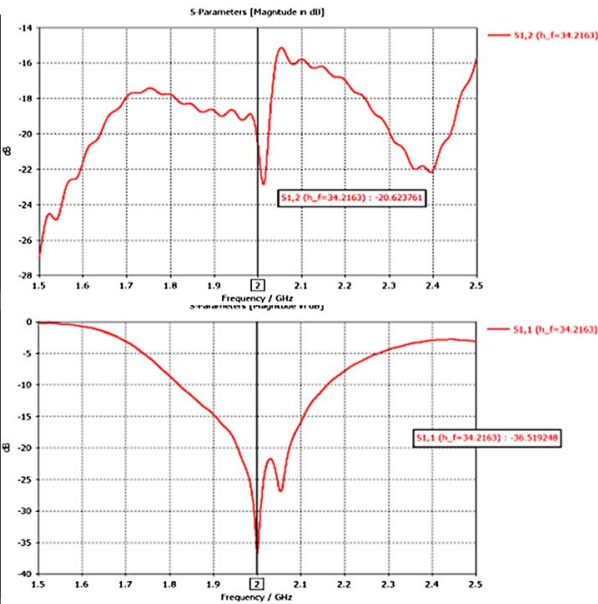

(b)

Fig. 11 Simulated values of the $S_{11}$ and $S_{12}$ parameters of the designed antennas: a plastic core antenna and $\mathbf{b}$ void core antenna

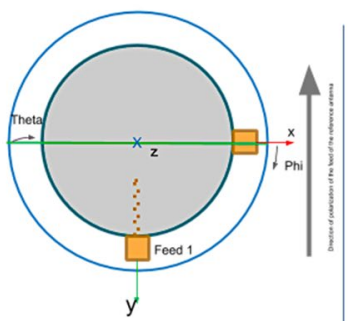

(a)

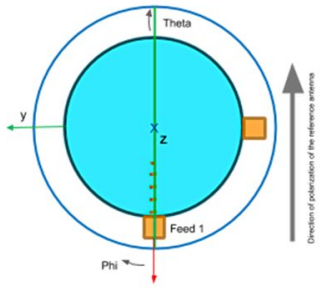

(b)
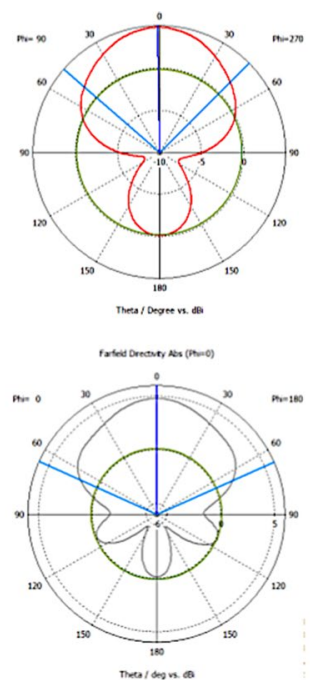

(c)
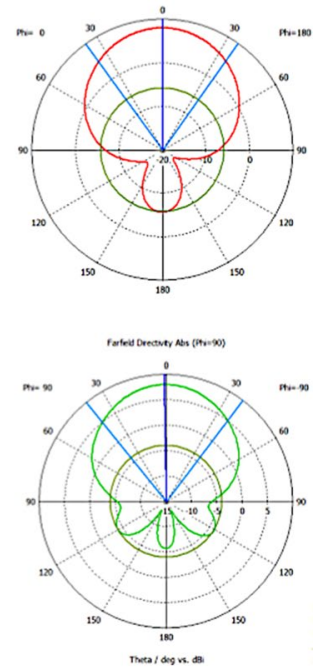

(d)

Fig. 12 Simulated values of the radiation pattern of the designed antennas: $\mathbf{a}, \mathbf{c}$ void core antenna and $\mathbf{b}$, d plastic core antenna coordinate reference system and radiation patterns 
Table 6 Main parameters referred to simulated radiation beam of the two antennas

\begin{tabular}{lllll}
\hline Antenna/polarization & $\begin{array}{l}\text { Main lobe magni- } \\
\text { tude }(\mathrm{dB})\end{array}$ & $\begin{array}{l}\text { Main lobe direc- } \\
\text { tion }\end{array}$ & $\begin{array}{l}\text { Angular width } \\
(3 \mathrm{~dB})\end{array}$ & $\begin{array}{l}\text { Side lobe } \\
\text { level }(\mathrm{dB})\end{array}$ \\
\hline Plastic core/parallel & 4.78 & $0^{\circ}$ & $94.4^{\circ}$ & -4.9 \\
Plastic core/orthogonal & 4.78 & $0^{\circ}$ & $131.7^{\circ}$ & -4 \\
Void core/parallel & 7.96 & $0^{\circ}$ & $71.3^{\circ}$ & -13.7 \\
Void core/orthogonal & 7.96 & $0^{\circ}$ & $76.3^{\circ}$ & -11.9 \\
\hline
\end{tabular}

radiation shape of both antennas was coherent with the diagrams of the standard, single feed, truncated circular waveguide antennas.

\subsection{Measured Results}

The comparison between measured and simulated $\mathrm{S}$ parameters are reported in Fig. 13.

Figure 14 depicts the radiation diagrams of the antennas. All the diagrams were measured for the angular intervals of $0^{\circ}-180^{\circ}$ and reflected for the intervals of $181^{\circ}-359^{\circ}$.

The measured values of the main parameters of radiation for both antennas are reported in Table 7 . The magnitudes of the main lobe values were significantly higher in all cases. For both antennas, the lobe opening angle slightly extended to $-3 \mathrm{~dB}$, except for the plastic core antenna with orthogonal polarization. The attenuation values of the secondary lobes in the plastic core antenna were significantly reduced but were higher for the void core antenna.

\subsection{Antennae Field Test}

To use the antennas on the remote sensing scanning device, a special mounting support on the three-axis mechanical handling system was designed using CAD/CAM (Computer-Aided Design, Computer-Aided Modelling) and 3D printing (Fig. 15a).

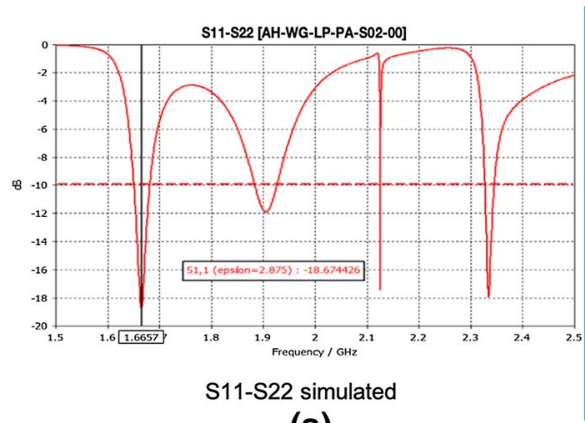

(a)

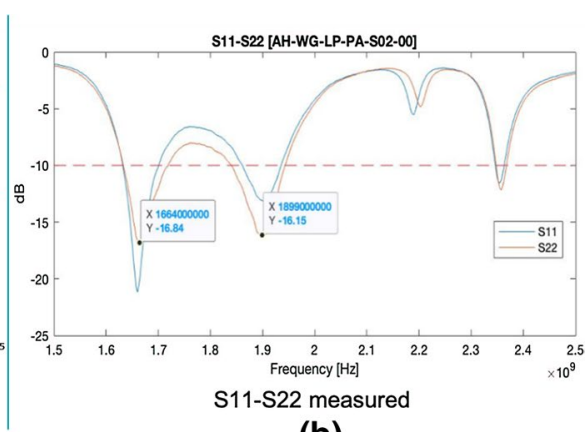

(b)

Fig. $13 S_{11}$ and $S_{22}$ parameters of the prototype of holographic antenna: a simulated; $\mathbf{b}$ measured 


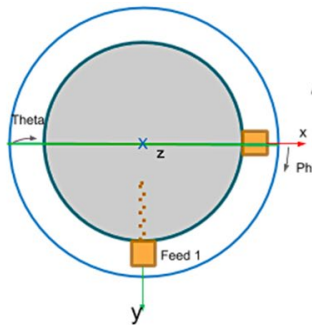

(a)

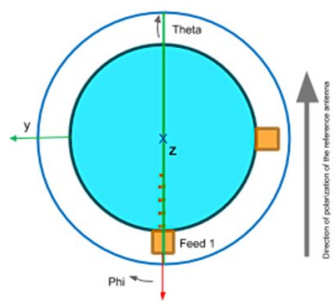

(b)
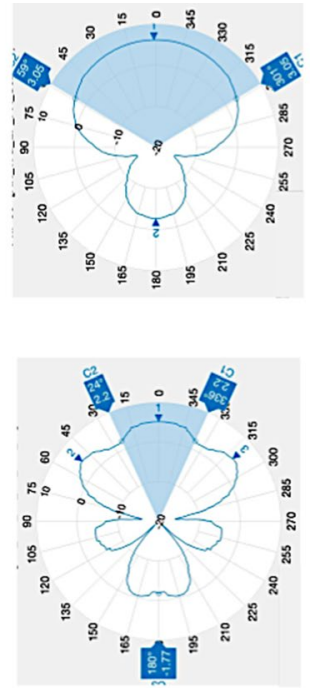

(c)
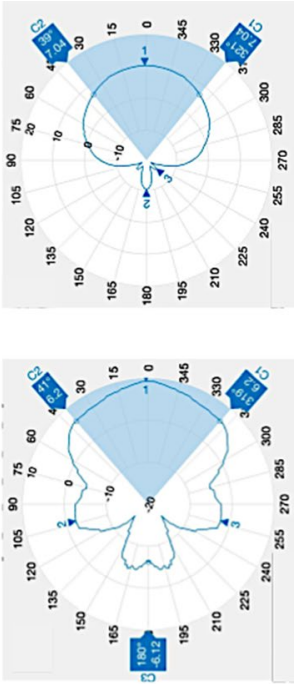

(d)

Fig. 14 Measured values of the radiation pattern of the designed antennas: $\mathbf{a}, \mathbf{c}$ void core antenna and $\mathbf{b}$, d plastic core antenna coordinate reference system and radiation patterns

Table 7 Main parameters of the radiation beam of the built antennas

\begin{tabular}{llllc}
\hline Antenna/polarization & $\begin{array}{l}\text { Main lobe magni- } \\
\text { tude }(\mathrm{dB})\end{array}$ & $\begin{array}{l}\text { Main lobe direc- } \\
\text { tion }\end{array}$ & $\begin{array}{l}\text { Angular width } \\
(3 \mathrm{~dB})\end{array}$ & $\begin{array}{l}\text { Side lobe } \\
\text { level }(\mathrm{dB})\end{array}$ \\
\hline Plastic core/parallel & 6.2 & $0^{\circ}$ & $118^{\circ}$ & -1.05 \\
Plastic core/orthogonal & 5.1 & $0^{\circ}$ & $48^{\circ}$ & -1.8 \\
Void core/parallel & 10.3 & $0^{\circ}$ & $78^{\circ}$ & -20.7 \\
Void core/orthogonal & 9.3 & $0^{\circ}$ & $76.3^{\circ}$ & -11.6 \\
\hline
\end{tabular}

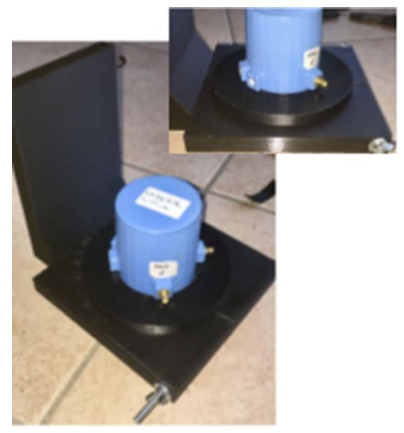

(a)

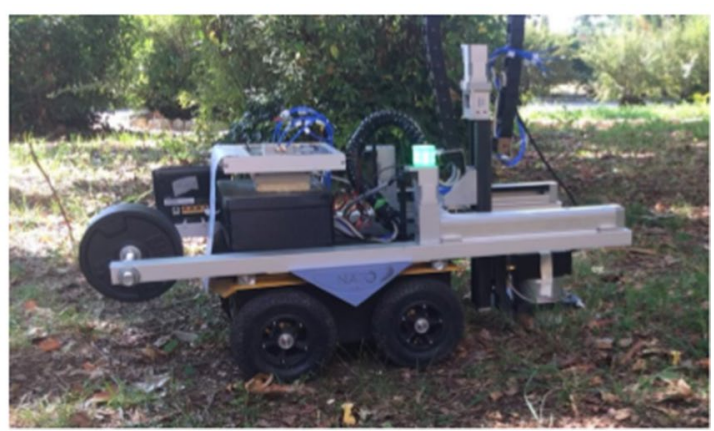

(b)

Fig. 15 The complete scanning system mounted on a remotely controlled robotic platform (Jackal, Clearpath): a 3D printed adaptor for installing the 3D printed radar antenna; b Ugo 1st robotic system with holographic radar mounted in the test field set up in the garden of the School of Engineering of the University of Florence, Italy

\section{刑 Springer}


A holographic radar, consisting of antenna, control and interface electronics, and mechanical handling system, was installed on the Ugo 1st robotic system (see Fig. 15b).

The acquisition process requires about three minutes for obtaining a 1984-pixel raw data image. The collected data were elaborated in real-time and displayed on the remote-control monitor developed in Python language as a web interface.

Laboratory experiments were carried out with an object on the floor served as the first experimental verification of the behavior of the two antennas. The acquisitions show comparable dynamics, represented in terms of gray levels. The shape and size of the targets are detectable even when the target has a complex profile, such as the perforated metal square. The acquisitions conducted on the external test field are made to simulate an operational context as similar as possible to a real minefield. Buried in the ground, about $3 \mathrm{~cm}$ deep, is an anti-personnel mine simulant with electromagnetic characteristics equivalent to real mines. In this environment, the reading of the images acquired with the imaging system is more complex, as there are many degrading effects for the signal that significantly decrease the Signal-Noise ratio: the reflection of the ground surface and its surface irregularity which is of comparable size with the wavelength of the radar signal, they generate diffraction phenomena. The soil, which is a highly dispersive propagation medium, determines a strong attenuation of the signal [27-29].

Each acquisition is reported in terms of in phase (I) and in quadrature (Q) components [30], and the images represent a gray level color scale. The knowledge of the I and Q components allows the application of the holographic technique, which allows the reconstruction of the reflecting objects (i.e., the distribution of the dielectric discontinuities) at a desired distance and therefore the reconstruction, where the information is available, of the three-dimensional scene. The non-idealities of the antennas could be modeled through a mathematical algorithm, such as the different sensitivities of the radiating element from the center toward the outside of the aperture or the geometric divergence of the radiated beam [3].

\subsubsection{Image Acquisitions in Laboratory}

The first part of the acquisitions was performed in the laboratory that ensure a control of the environmental factor being indoor. The robotic system was positioned on a terracotta floor and a target was positioned on the floor surface. Two targets were chosen: a plastic target, which was a $78 \times 20 \mathrm{~mm}^{2}(\mathrm{D} \times \mathrm{h})$ circular candy box, shown in Fig. 16a, which we defined as target "A", and a square metal target, with dimensions of $130 \times 130 \times 10 \mathrm{~mm}^{3}$ and holes of different diameters, shown in Fig. 16b, which we defined as target "B".

Figures 17 and 18, respectively, represent the acquisitions of targets A and B with the plastic core antenna and the void core antenna. For all acquisitions, the antenna aperture that corresponded with the scanning plane was placed $30 \mathrm{~mm}$ from the ground, which is immediately after the reactive near-field distance of the antenna radiation (about $24 \mathrm{~mm}$ ). We performed acquisitions for four frequencies $(1.63,1.66$, $1.85,1.90 \mathrm{GHz}$ for the plastic core antenna and $1.80,1.85,1.90,2.00 \mathrm{GHz}$ for the void core antenna) chosen closer the minimum peaks of $S_{11}$ parameter. The images 


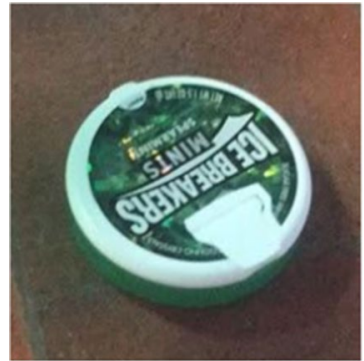

(a)

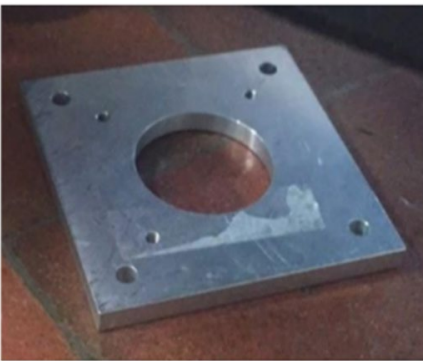

(b)

Fig. 16 Targets used for generation of dielectric discontinuities images: a target A: a plastic box; $\mathbf{b}$ target B: a steel piece with some holes

report the acquisition frequency at the top and the analysis parameters (dynamic, mean, and variance) at the bottom.

\subsubsection{Images Acquisitions on a Test Field}

To highlight the behavior of the scanning system for microwave imaging under real conditions, the acquisitions of an object buried for over 12 months in the garden of the School of Engineering in Florence are reported. This object was a circular tin box with a diameter of $100 \mathrm{~mm}$ and a height of $50 \mathrm{~mm}$. The object was initially buried $30 \mathrm{~mm}$ deep to simulate the location of a metal-type mine. The images were captured in dry ground conditions, with an outdoor temperature of $27{ }^{\circ} \mathrm{C}$.

Figure 19 shows the acquisitions from the two antennas with the scanning plane positioned $30 \mathrm{~mm}$ from the ground plane. The effects of the attenuation introduced by the soil are clearly visible in terms of reduced dynamics of the images (in this case, it is mainly clayey soil). The purpose of this study was not to highlight the attenuative phenomena that occur due to the interaction between soil and microwaves; however, we highlight how the inhomogeneity of the medium, the air-soil interfaces reflectivity, and the moisture of the soil bottom the surface, which are all variable and not predeterminable parameters, affects the quality of the scanned images.

\section{Discussion}

\subsection{Plastic Core Antenna Simulation to Identify and Quantify the Geometric Parameters That Best Approximate the Measured Behavior}

The simulation results provide (Fig. 11) two antennas with a $-10 \mathrm{~dB}$ bandwidth greater than $150 \mathrm{MHz}$ for the plastic core one and more than $350 \mathrm{MHz}$ for the metal void core antenna at a centered bandwidth of $2 \mathrm{GHz}$. The simulated main lobe aperture of the plastic core antenna greater than $40^{\circ}$ compared to the metal void core antenna. 

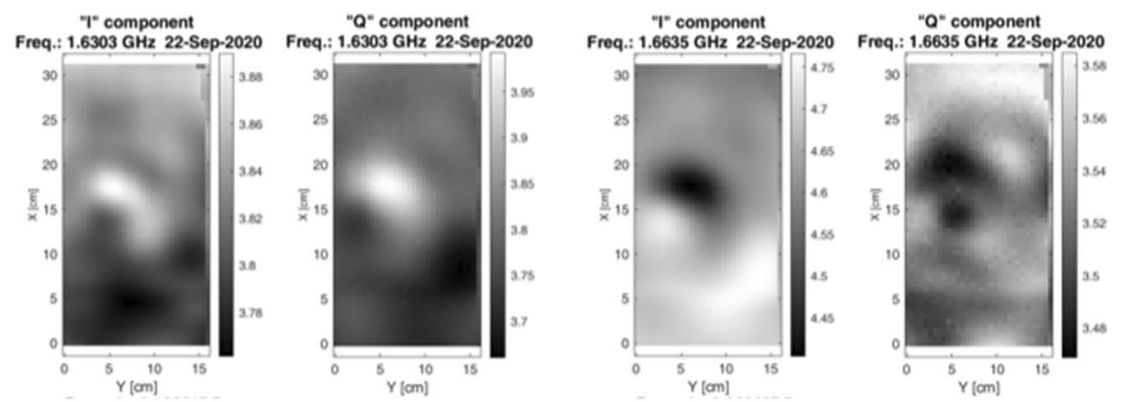

(a)
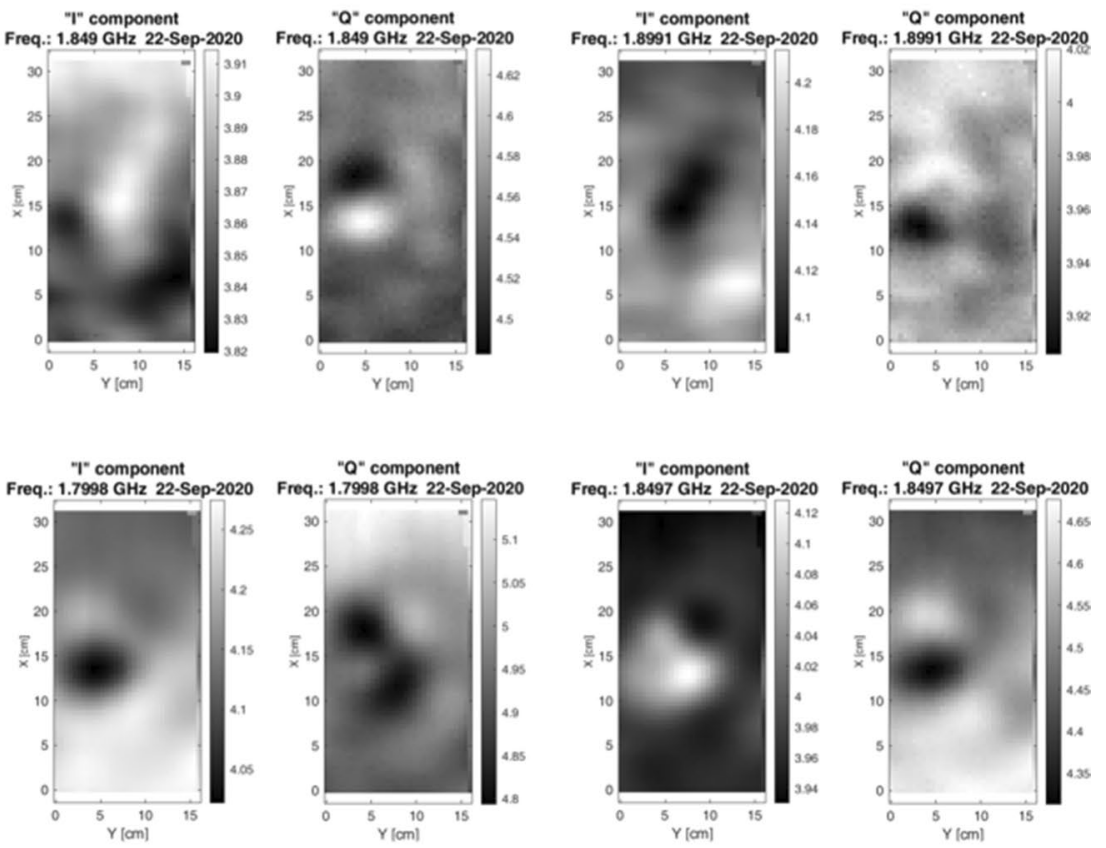

"Q" component

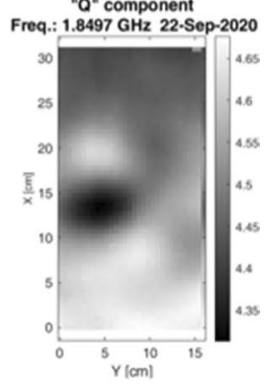

(b)
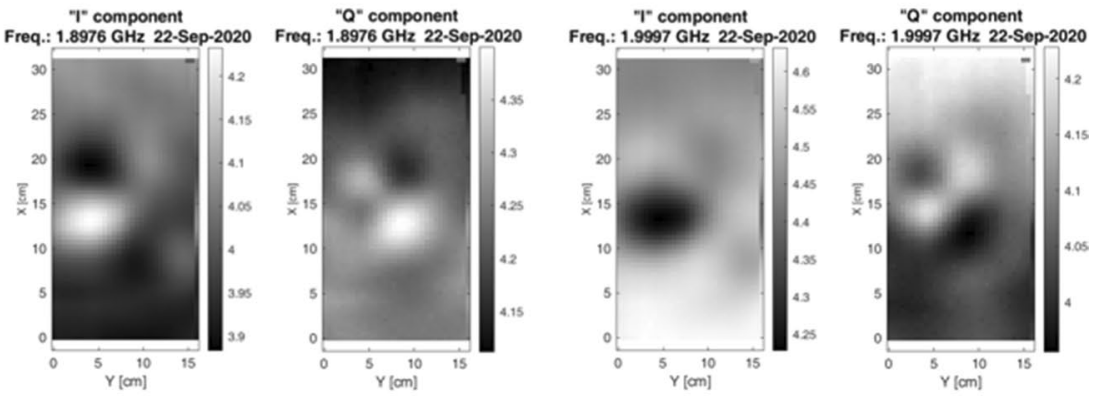

Fig. 17 Images of target A at a height of $30 \mathrm{~mm}$ from the ground. Acquisitions at frequencies: 1.63, 1.66, $1.85,1.90 \mathrm{GHz}$, for the plastic core antenna (a) and 1.80, 1.85, 1.90, $2.00 \mathrm{GHz}$ for the void core antenna (b). The images report the acquisition frequency at the top and the signal amplitude dynamic in the grayscale 

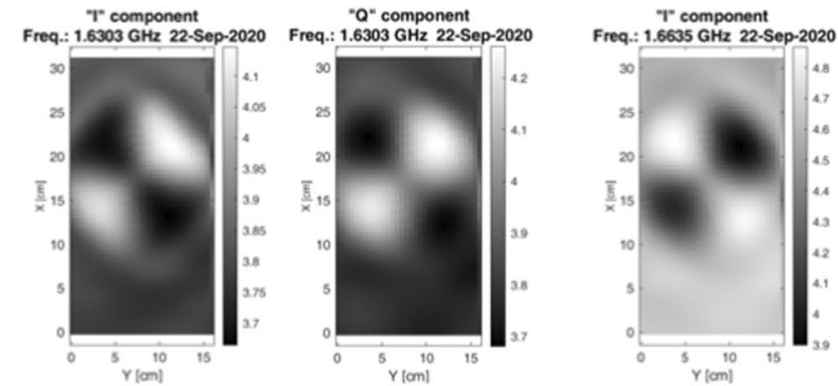

"Q" component

(a)

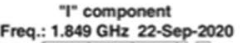

"Q" component

Freq.: 1.849 GHz 22-Sep-2020
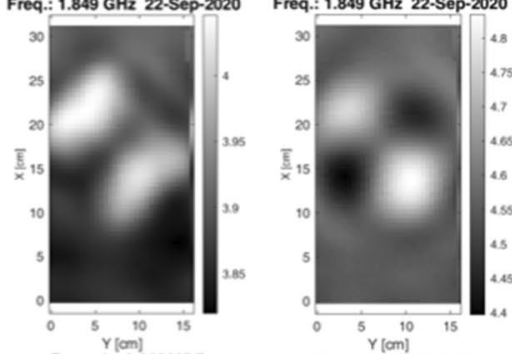

"I" component

Freq.: $1.8991 \mathrm{GHz} 22-\mathrm{Sep}-2020$ Freq.: $1.8991 \mathrm{GHz} 22-\mathrm{Sep}-2020$
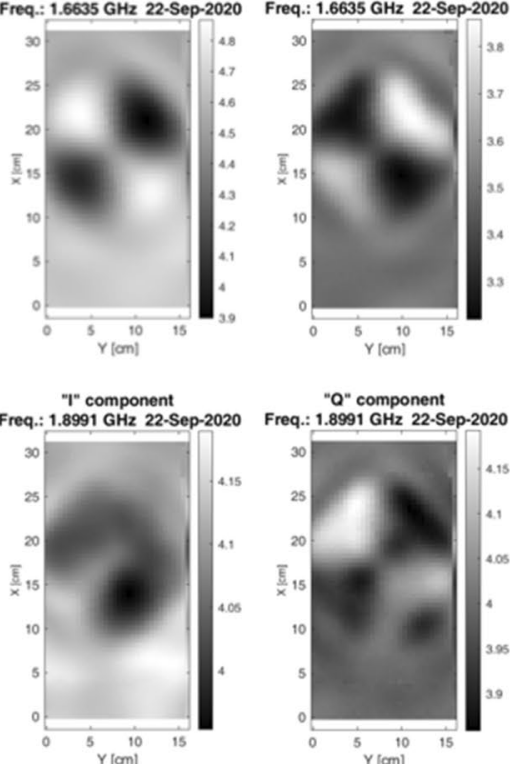

"Q" component

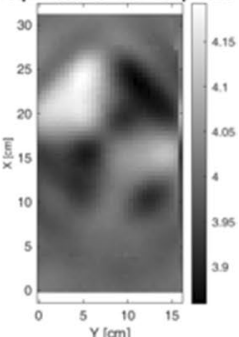

T" component

Freq.: 1.7998 GHz 22-Sep-2020

"Q" component Freq.: 1.7998 GHz 22-Sep-2020

"I" component

"Q* component
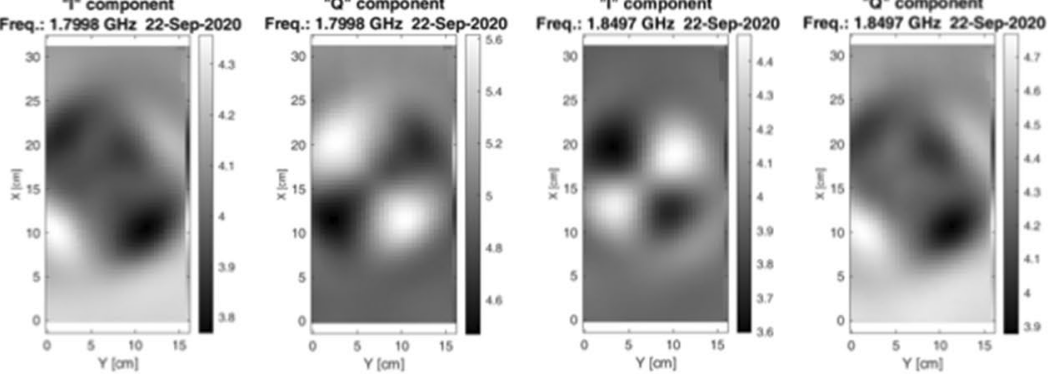

(b)
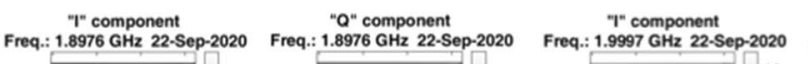

" $\mathrm{Q}$ " component

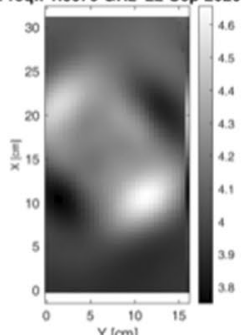

Dynamic: $0.9085[\mathrm{~V}]$

Mean: $4.1286[\mathrm{~V}]$

Variance: $170.3387\left[\mathrm{uV}^{2}\right]$

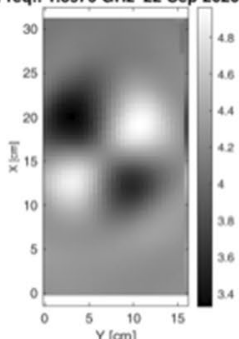

\section{Dynamic: 1.6339 [V]}

Mean: 4.2011 [V]

Variance: $2703.9893\left(u V^{2}\right]$

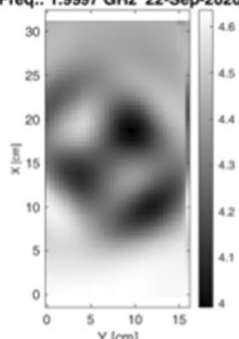

Dynamic: $0.64541[\mathrm{~V}]$

Mean: $4.3804[\mathrm{~V}]$

Variance: $31.4005\left[\mathrm{uV}^{2}\right]$

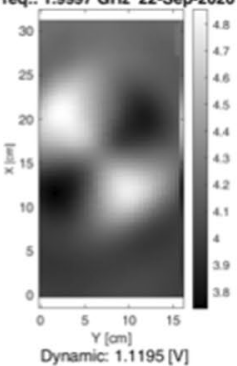

Dynamic: $1.1195[\mathrm{~V}]$

Mean: 4.2011 [V]

Variance: $971.2943\left[\mathrm{uV}^{2}\right]$

Fig. 18 Images of target A at a height of $30 \mathrm{~mm}$ from the ground. Acquisitions at frequencies: 1.63, 1.66, $1.85,1.90 \mathrm{GHz}$, for the plastic core antenna (a) and 1.80, 1.85, 1.90,2.00 GHz for the void core antenna (b). The images report the acquisition frequency at the top and the signal amplitude dynamic in the grayscale 
The measurement results (Fig. 11) that the plastic core antenna has a different frequency behavior than the simulated one and for this reason we have investigated and modified the simulation parameters for match the $S_{11}$ and $S_{22}$ parameters of the antenna with the measured ones. We first focused on the construction of the plastic core antenna. We assumed a dielectric constant of 2.5 for the plastic material [31]. To evaluate which parameters caused the different $S_{11}$, the feed lengths were varied in the simulator. For both antennae, we found that the measured feed length was $2 \mathrm{~mm}$ shorter than the simulated feed length.

By simulating feeds longer than $2 \mathrm{~mm}$ for the void core antenna, return loss values equivalent to those measured were obtained, with the minimum value in the band $(1.5,2.5) \mathrm{GHz}$ coinciding. In the simulated diagram, the minimum is located at $1.894 \mathrm{GHz}$, whereas the measured minimum was located at $1.899 \mathrm{GHz}$. For the plastic core antenna, however, this optimization was not sufficient to reach the measured values. We needed to change the dielectric constant. By simulating increasing dielectric constant values for the material, we arrived at a value of $\varepsilon_{\mathrm{r}}=2.875$, which accurately approximated the diagram constructed from the measurements in the anechoic chamber.

By applying this value as the dielectric constant, a simulated minimum value was obtained $(1.666 \mathrm{GHz})$. The measured minimum value was located $1.664 \mathrm{GHz}$, and the simulated and measured value curve profiles were in agreement.

For both antennas, the measurements showed a slight increase, $1 \mathrm{~dB}$ in the main radiation direction, while the metal antenna showed a very attenuated level of the secondary radiation lobes in parallel polarization (about $-8 \mathrm{~dB}$ ) compared to the simulated model. And the plastic core antenna instead showed secondary radiation lobes with a higher level than expected in the simulator. This could be linked to the use of a conductive paint that is not sufficiently shielding or in any case of insufficient thickness.

In the field tests (referring to Fig. 19), comparing the images of component I at the center band frequency of the two antennas $(1.66 \mathrm{GHz}$ for the plastic core antenna and $1.99 \mathrm{GHz}$ for the void core) the dynamic is $0.4 \mathrm{~V}$ for the metal one, $0.36 \mathrm{~V}$ for the plastic one. With reference to the metal target (Fig. 18), always at the center band frequency for each antenna, the dynamic of the plastic antenna image has a value of $0.97 \mathrm{~V}$ while the void core of $0.65 \mathrm{~V}$. The same comparison with the scanning in the natural soil, on the anti-personnel mine simulant, shows a value of $0.29 \mathrm{~V}$ for the plastic core antenna dynamic and $0.20 \mathrm{~V}$ for the void core antenna.

\section{Conclusions}

This paper investigates the performance of a metalized 3D-printed antenna in comparison to a reference metallic antenna for subsurface microwave imaging at operating frequencies of around $2 \mathrm{GHz}$. Thanks to the printable material with a higher dielectric permittivity, we built a plastic core antenna with a reduced diameter by more than 53\% which makes it more suitable to exploit the scanning aperture of the robotic platform or allows it to be more agile when mounted at the boom tip of a handheld scanner, similarly to a metal detector. 
Fig. 19 Images of landmine simulant (PMN-4 type) at a height of $30 \mathrm{~mm}$ from the ground. Acquisitions at frequencies: 1.63,1.66, 1.85, $1.90 \mathrm{GHz}$, for the plastic core antenna (a) and 1.80, 1.85, 1.90, $2.00 \mathrm{GHz}$ for the void core antenna (b). The images report the acquisition frequency at the top and the signal amplitude dynamic in the grayscale

The measurement in the anechoic chamber showed that the void core antenna has a $-10 \mathrm{~dB}$ return loss band $>300 \mathrm{MHz}$ and the plastic core antenna has a band $>150 \mathrm{MHz}$. The plastic core antenna has a reduced main lobe radiated power of about $-5 \mathrm{~dB}$ and a higher aperture angle of the main lobe of $40^{\circ}$. The reduced radiated power, in the near filed operating conditions does not have a significative impact in the images' information.

Comparison of the acquired images of representative targets could be conducted based on quantitative and qualitative aspects. In the acquisitions both in a controlled environment and in the field test, the morphology of the recorded objects was clearly distinguishable, and the signal-to-noise ratio was comparable between the two antennas. In the outdoor field experiments no remarkable disturbing effects were observed due to the presence of natural material on the surface of the soil (leaves, grass, stones, etc.).

In conclusion, this work represents a first step toward evaluating the possibility of applying this technology. Observing the results, we found that the 3D printing process could be used to produce more compact antennas that are easily adaptable to different applications in remote sensing. Filament printing technology allows us to create complex geometries with relative simplicity of modification and optimization in order to obtain easily customizable antennas for specific applications. This approach, when applied to an imaging method on robotic platforms or with portable instruments can simplify the integration of more system components (the housing for the radio frequency front end electronics but also other sensors, handling supports, etc.). Moreover, the absence of assembled parts in plastic metalized waveguide antennas guarantees better mechanical strength, making them very resistant to the mechanical stresses that are inevitable in field use.

The encouraging results allow us to think about the next steps in further exploiting the properties of printable plastic materials: The availability of filaments of composite materials for 3D printing, specially made for use in radiofrequency applications with high (up to 10) certified dielectric permittivity, allows, for example, the development of smaller and lighter (varying the material density) prototypes. Three-dimensional construction technology can allow us to create models adapted to different remote sensing devices that can be continuously improved and spread even in geographical areas with limited technological and economic resources. 

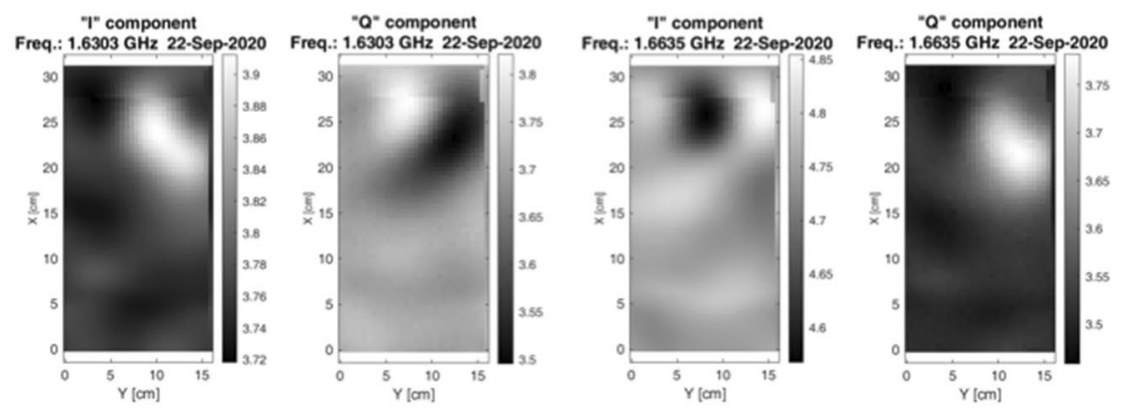

(a)
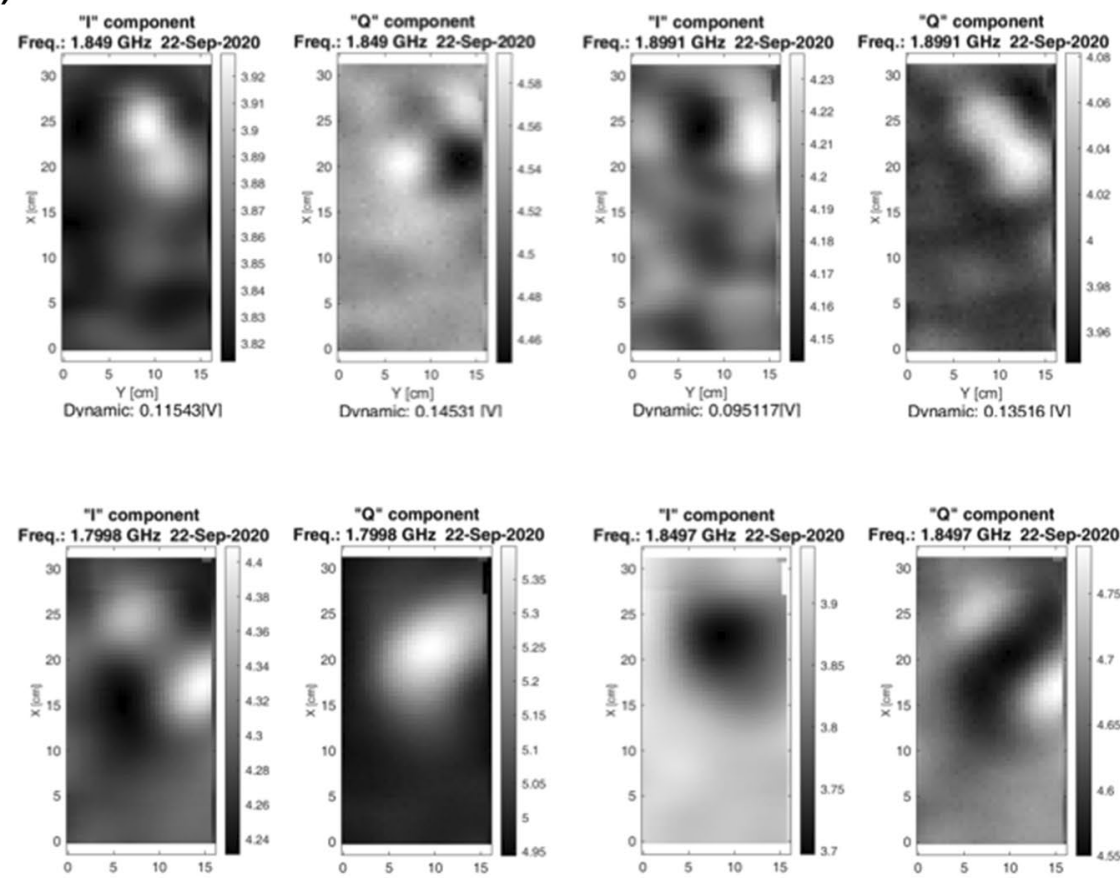

(b)
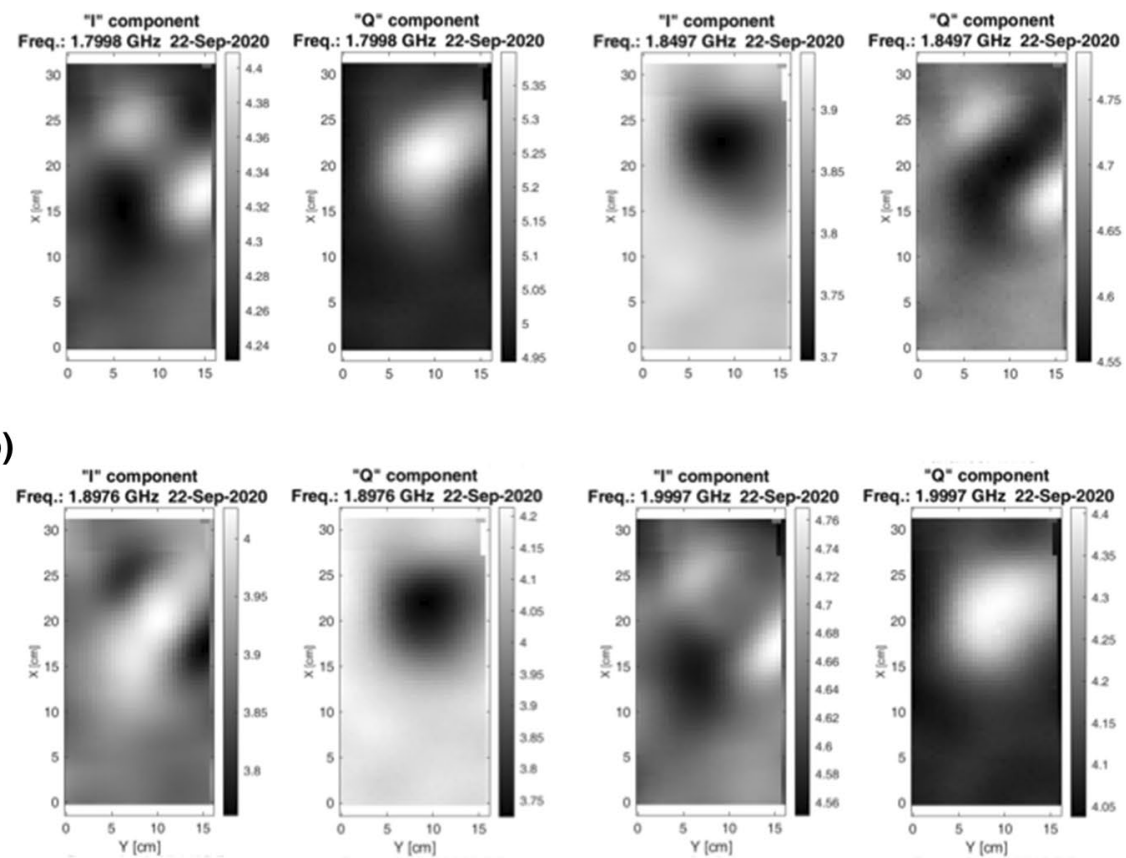
Acknowledgements We thank Professor Angelo Freni, head of the joint lab of DINFO: Mini-invasive energetic technologies for oncologic therapy - MIET. NATO Science for Peace and Security. Ente Cassa di Risparmio di Firenze.

Author Contributions Conceptualization, L.B., P.F., and L.C.; methodology, L.B., P.F., and L.C.; software, L.B.; validation, L.B., P.F., and L.C.; formal analysis, L.B.; investigation, L.B., P.F., S.P., and R.O.; resources, L.B.; data curation, L.B.; writing-original draft preparation, L.B.; writing-review and editing, L.B., R.O., and L.C.; supervision, L.C. All authors have read and agreed to the published version of the manuscript.

Funding Open access funding provided by Università degli Studi di Firenze within the CRUI-CARE Agreement. NATO G-5731 "Multi-sensor cooperative robots for shallow buried explosive threat detection", 2020-2022; Ente Cassa di Risparmio di Firenze "BIG DATA" project.

\section{Declarations}

Conflict of interest The authors declare no conflict of interest. The funders had no role in the design of the study; in the collection, analyses, or interpretation of data; in the writing of the manuscript, or in the decision to publish the results.

Open Access This article is licensed under a Creative Commons Attribution 4.0 International License, which permits use, sharing, adaptation, distribution and reproduction in any medium or format, as long as you give appropriate credit to the original author(s) and the source, provide a link to the Creative Commons licence, and indicate if changes were made. The images or other third party material in this article are included in the article's Creative Commons licence, unless indicated otherwise in a credit line to the material. If material is not included in the article's Creative Commons licence and your intended use is not permitted by statutory regulation or exceeds the permitted use, you will need to obtain permission directly from the copyright holder. To view a copy of this licence, visit http://creativecommons.org/licen ses/by/4.0/.

\section{References}

1. Capineri, L., \& Turmuş, E. K. (Eds.). (2019). Explosives detection: Sensors, electronic systems and data processing. Dordrecht: Springer. https://doi.org/10.1007/978-94-024-1729-6

2. Ivashov, S. I., Razevig, V. V., Vasiliev, I. A., Zhuravlev, A. V., Bechtel, T. D., \& Capineri, L. (2011). Holographic subsurface radar of RASCAN Type: Development and applications. IEEE Journal of Selected Topics in Applied Earth Observations and Remote Sensing, 4(4), 763-778. https://doi.org/ 10.1109/JSTARS.2011.2161755

3. Borgioli, G., Bossi, L., Capineri, L., Falorni, P., Bechtel, T., Crawford, F., Inagaki, M., Pochanin, G., Ruban, V., Varyanitza-Roschupkina, L., \& Ogurtsova, T. (2018). A hologram reconstruction algorithm for landmine recognition and classification based on microwave holographic radar data. Progress in Electromagnetic Research Symposium (PIERS-Toyama), 1938-1944. https://doi.org/10. 23919/PIERS.2018.8597707.

4. Group, T. M. (n.d.). Practical 3D printing of antennas and RF electronics. Retrieved June 1, 2020, from https://www.aerodefensetech.com/component/content/article/adt/features/articles/37095.

5. Zhang, S., Arya, R. K., Pandey, S., Vardaxoglou, Y., Whittow, W., \& Mittra, R. (2016). 3D-printed planar graded index lenses. IET Microwaves, Antennas \& Propagation, 10(13), 1411-1419. https:// doi.org/10.1049/iet-map.2016.0013

6. Malik, B. T., Doychinov, V., Zaidi, S. A. R., Robertson, I. D., \& Somjit, N. (2019). Antenna gain enhancement by using low-infill 3D-printed dielectric lens antennas. IEEE Access, 7, 102467102476. https://doi.org/10.1109/ACCESS.2019.2931772 
7. Anwar, M. S., Abufanas, H., \& Bangert, A. (2020). 3D printed dielectric lens for the gain enhancement of a broadband antenna. International Journal of RF and Microwave Computer-Aided Engineering. https://doi.org/10.1002/mmce.22115

8. Artemenko, A., Mozharovskiy, A., Maltsev, A., Maslennikov, R., Sevastyanov, A., \& Ssorin, V. (2012). 2D electronically beam steerable integrated lens antennas for mmWave applications. Presented at the 2012 42nd European Microwave Conference (EuMC 2012), 213-216. https://doi.org/ 10.23919/EuMC.2012.6459155.

9. Nguyen, N. T., Rolland, A., Boriskin, A. V., Valerio, G., Le Coq, L., \& Sauleau, R. (2012). Size and weight reduction of integrated lens antennas using a cylindrical air cavity. IEEE Transactions on Antennas and Propagation, 60(12), 5993-5998. https://doi.org/10.1109/TAP.2012.2208931

10. Mazzinghi, A., Blaschi, L., \& Freni, A. (2018). Three-dimensional printed low-cost high-gain antennas. IEEE Antennas and Wireless Propagation Letters, 17(11), 2145-2149. https://doi.org/10. 1109/LAWP.2018.2841775

11. Kim, O. S. (2014). Rapid prototyping of electrically small spherical wire antennas. IEEE Transactions on Antennas and Propagation, 62(7), 3839-3842. https://doi.org/10.1109/TAP.2014.2317489

12. Schwarz, U., Helbig, M., Sachs, J., Seifert, F., Stephan, R., Thiel, F., \& Hein, M. A. (2008). Physically small and adjustable doubleridged horn antenna for biomedical UWB radar applications. 2008 IEEE international conference on ultra-wideband, (vol. 1, pp. 5-8). https://doi.org/10.1109/ ICUWB.2008.4653272.

13. Otter, W. J., \& Lucyszyn, S. (2016). 3-D printing of microwave components for 21 st century applications. 2016 IEEE MTT-S international microwave workshop series on advanced materials and processes for RF and THz applications (IMWS-AMP), 1-3. https://doi.org/10.1109/IMWS-AMP. 2016.7588327.

14. Robb, G. (n.d.). Assemble antennas with 3D printing (2018). Microwaves \&RF. Retrieved May 6, 2021, from https://www.mwrf.com/technologies/systems/article/21849379/assemble-antennas-with3d-printing.

15. Bjorgaard, J., Hoyack, M., Huber, E., Mirzaee, M., Chang, Y.-H., \& Noghanian, S. (2018). Design and fabrication of antennas using 3D printing. Progress in Electromagnetics Research C, 84, 119134. https://doi.org/10.2528/PIERC18011013

16. 3D Filaments for Quick Prototyping I PREPERM® Webshop. (n.d.). Retrieved September 25, 2020, from https://www.preperm.com/webshop/product-category/3d-filaments/.

17. Taylor, J. D. (Ed.). (2012). Ultrawideband radar: Applications and design. Boca Raton, FL: Taylor \& Francis.

18. Dassault Systeme, CST Microwave Studio. (n.d.). Software for electromagnetic simulation and analysis 3D CST Studio Suite. Retrieved November 30, 2020, from https://www.3ds.com/it/prodo tti-e-servizi/simulia/prodotti/cst-studio-suiter/.

19. 841AR - Super Shield ${ }^{\mathrm{TM}}$ Nickel Conductive Paint - Acrylic Conductive Coatings (AR Series)|MG Chemicals. (n.d.). Retrieved September 17, 2020, from https://www.mgchemicals.com/products/ emi-and-rfi-shielding/acrylic-conductive-coatings-ar-series/841ar-super-shield-nickel-conductivecoating.

20. A8 FDM 3D Printer|Full DIY Desktop Cheap 3d printer-Anet Store. (n.d.). Retrieved September 17, 2020, from https://www.anet3d.com/product/most-popular-anet-a8-diy-fdm-3d-printer/.

21. Home IFAC. (n.d.). Retrieved September 17, 2020, from http://www.ifac.cnr.it/.

22. Ackermann, G., \& Eichler, J. (2007). Holography: A practical approach. Chichester: Wiley.

23. Amineh, R. K., Ravan, M., Sharma, R., \& Baua, S. (2018). Three-dimensional holographic imaging using single frequency microwave data. International Journal of Antennas and Propagation, 2018, 1-14. https://doi.org/10.1155/2018/6542518

24. Amineh, R. K., Ravan, M., Khalatpour, A., \& Nikolova, N. K. (2011). Three-dimensional near-field microwave holography using reflected and transmitted signals. IEEE Transactions on Antennas and Propagation, 59(12), 4777-4789. https://doi.org/10.1109/TAP.2011.2165496

25. Holographic and Impulse Subsurface Radar for Landmine and IED Detection. (n.d.). Retrieved September 17, 2020, from http://www.nato-sfps-landmines.eu/.

26. Daniyan, O. L., Opara, F. E., Okere, B. I., Aliyu, N., Ezechi, N., Wali, J., Adejoh, J., Eze, K., Chapi, J., Justus, C., \& Adeshina, K. O. (2014). Horn antenna design. International Journal of Emerging Technology and Advanced Engineering, 4(5), 706-708

27. Bechtel, T., Truskavetsky, S., Capineri, L., Pochanin, G., Simic, N., Viatkin, K., Sherstyuk, A., Byndych, T., Falorni, P., Bulletti, A., Giannelli, P., Ruban, V., Varyanitza-Roschupkina, L., \& Bechtel, M. (2016). A survey of electromagnetic characteristics of soils in the Donbass region (Ukraine) 
for evaluation of the applicability of GPR and MD for landmine detection. 2016 16th international conference on ground penetrating radar (GPR), 1-6. https://doi.org/10.1109/ICGPR.2016.7572688.

28. Bechtel, T., Truskavetsky, S., Pochanin, G., Capineri, L., Sherstyuk, A., Viatkin, K., Byndych, T., Ruban, V., Varyanitza-Roschupkina, L., Orlenko, O., Kholod, P., Falorni, P., Bulletti, A., Bossi, L., \& Crawford, F. (2019). Characterization of electromagnetic properties of in situ soils for the design of landmine detection sensors: application in Donbass, Ukraine. Remote Sensing, 11, 1232-1247. https://doi.org/10.3390/rs11101232

29. Qin, T., Bossi, L., Bartolini, A., Falorni, P., Giannelli, P., Zhao, Y., \& Capineri, L. (2018). Influence analysis of uneven surface on landmine detection using holographic radar. 2018 Progress in electromagnetics research symposium (PIERS-Toyama), 683-691. https://doi.org/10.23919/PIERS.2018. 8597927.

30. Bossi, L., Falorni, P., Bartolini, A., \& Capineri, L. (2020). Characterization of a 2 GHz holographic radar antenna for detection of subsurface targets. 18th international conference on ground penetrating radar, 324-327. https://doi.org/10.1190/gpr2020-085.1.

31. Veselý, P., Tichý, T., Śefl, O., \& Horynová, E. (2018). Evaluation of dielectric properties of 3D printed objects based on printing resolution. IOP Conference Series: Materials Science and Engineering, 461, 012091. https://doi.org/10.1088/1757-899X/461/1/012091

Publisher's Note Springer Nature remains neutral with regard to jurisdictional claims in published maps and institutional affiliations.

\section{Authors and Affiliations}

\section{Luca Bossi $^{1}$ (D) Pierluigi Falorni ${ }^{1} \cdot$ Saverio Priori ${ }^{2} \cdot$ Roberto Olmi $^{2}$. Lorenzo Capineri ${ }^{1}$}

Pierluigi Falorni

p.falorni@gmail.com

Saverio Priori

S.Priori@ifac.cnr.it

Roberto Olmi

r.olmi@ifac.cnr.it

Lorenzo Capineri

lorenzo.capineri@unifi.it

1 Università degli Studi di Firenze, Florence, Italy

2 Institute of Applied Physics, Sesto Fiorentino, FI, Italy 